\title{
Sphingosine-1-phosphate receptors 1 and 3 regulate the expression of scavenger receptor B1 in human aortic endothelial cells
}

Dongdong Wang, Lucia Rohrer, Arnold von Eckardstein*

Institute of Clinical Chemistry, University Hospital Zurich, Wagistrasse 14, 8952 Schlieren, Switzerland.

*Correspondence to: Arnold von Eckardstein, Institute of Clinical Chemistry, University Hospital Zurich, Raemistrasse 100, 8091 Zurich, Switzerland.

Email: arnold.voneckardstein@usz.ch

Running title: S1PRs regulate SR-B1 expression in HAECs

Abbreviations: Akt, protein kinase B; cAMP: cyclic AMP; HAEC: human aortic endothelial cells; HDL: high-density lipoprotein; LDL: low-density lipoprotein; LXR: liver X receptor; MEK: extracellular signalregulated kinase kinase; p38 MAPK: p38 mitogen-activated protein kinase; RLU: relative luminescence; RXR: retinoid X receptor; S1P: Sphingosine-1-phosphate; S1PR: Sphingosine-1-phosphate receptor; siRNA: small interfering RNA; SR-B1: scavenger receptor class B type 1;

Main text: 3432 words, 54 references, 5 main figures, 3 supplementary figures 


\section{Abstract (192 words)}

Several vasoprotective functions of high-density lipoproteins (HDL) on the endothelium have been shown to depend on the presence of sphingosine-1-phosphate (S1P) receptors (S1PRs) as well as scavenger receptor class B type 1 (SR-B1). Interference with the presence of S1P or the activity of S1PR1 or S1PR3 mimics many effects seen by the interference with SR-B1. This raises the question on interactions between S1P receptors and SR-B1. We investigated the influence of S1PRs on SR-B1 expression in human aortic endothelial cells. Silencing or pharmacological inhibition of S1PR1 or S1PR3 down-regulated SCARB1 mRNA expression as well as SR-B1 protein abundance. RNA interference with S1PR1 or S1PR3 also decreased cellular association of ${ }^{125} \mathrm{I}-\mathrm{HDL}$ with HAECs. Further mechanistic studies showed that knockdown of S1PR1 or S1PR3 reduced SR-B1 protein by inducing its degradation through deceasing Akt activity. Moreover, silencing of S1PR1 or S1PR3 suppressed SCARB1 mRNA expression by decreasing cellular cAMP levels. In conclusion, we provide evidence for an as yet unappreciated interaction, namely the regulation of SR-B1 abundance by S1PRs on both transcriptional and post-translational levels, suggesting that interactions of S1PRs and SR-B1 regulate signaling functions of HDL as well as uptake of lipoproteins in endothelial cells.

Key words: high-density lipoprotein, cardiovascular disease, Akt, cyclic AMP, vascular function. 


\section{INTRODUCTION}

Scavenger receptor class B type 1 (SR-B1) is a member of cluster of differentiation 36 (CD36) superfamily (1). The SR-B1 encoding SCARB1 gene is expressed in many tissues and cell types, including liver, steroidogenic tissues, macrophages, and endothelial cells (2-4). SR-B1 is a multifunctional receptor which is involved in the pathogenesis of atherosclerosis but also other diseases including cancer $(2,3,5)$. The prototype function is the mediation of cholesterol flux into and out of cells $(1,3)$. SR-B1 mediates the selective uptake of cholesteryl esters mostly from high-density lipoproteins (HDL) into liver, adrenals, testes, or ovaries which use cholesterol for the formation of bile and steroid hormones, respectively $(1,3$, 6, 7). From macrophages, endothelial and other cells, SR-B1 rather mediates cholesterol efflux to HDL. The relative activity of cholesteryl ester consuming and producing enzymes in the cell and the plasma appear to dictate the directionality of the flux (1). The presence or absence of SR-B1, however, also affects other cellular functions either indirectly through changes in the distribution of cholesterol within the cell and cell membrane or directly by interaction with adapter proteins such as PDZK1 or DOCK4 (8-10).

In endothelial cells, SR-B1 regulates the uptake of both LDL and HDL for transendothelial transport (913). SR-B1 in endothelial cells was also found to be a limiting factor for the ability of HDL to promote nitric oxide production as well as proliferation and migration, and to inhibit cellular adhesion molecule, expression and, as the consequence, leukocyte transmigration $(10,14-19)$. These vasoprotective and antiinflammatory functions have also been assigned to sphingosine-1-phosphate (S1P) which is enriched in HDL through its binding to apolipoprotein M. S1P interacts with five different G-protein coupled S1P receptors $(18,20-24)$. They include S1PR1, S1PR2, and S1PR3 which are expressed in endothelial cells and regulate the development and function of the vasculature $(20,21)$. Interference with the presence of S1P or the activity of S1PR1 or S1PR3 mimics many effects seen by the interference with SR-B1. This raises the question on interactions between S1P receptors and SR-B1. For example, it has been suggested that SR-B1 tethers HDL on the cell surface and thereby increases the likelihood of S1P/S1P-receptor interaction $(2,25)$. We here investigated the influence of S1PRs on SR-B1 expression. 


\section{MATERIALS AND METHODS}

\section{Cell culture}

Human aortic endothelial cells (HAECs) from Cell Applications Inc. (304-05a) were cultured in endothelial basal medium (EBM)-2 (LONZA Clonetics ${ }^{\mathrm{TM}}$ CC-3156) with 5\% fetal bovine serum (GIBCO), supplemented with endothelial growth medium (EGM)-2 SingleQuots (LONZA Clonetics CC-4176) containing human epidermal growth factor (hEGF, CC-4317A), vascular endothelial growth factor (VEGF, CC-4114A), R3-insulin-like growth factor-1 (R3-IGF-1, CC-4115A), ascorbic acid (CC-4317A), hydrocortisone (CC-4112A), human fibroblast growth factor-beta (hFGF- $\beta$, CC-4113A), heparin (CC4396A), and gentamicin/amphotericin-B (GA-1000, CC-4381A) at $37^{\circ} \mathrm{C}$ in a humidified $5 \% \mathrm{CO}_{2}, 95 \%$ air incubator.

\section{Small interfering RNA (siRNA) transfection}

Endothelial cells were reverse transfected with siRNA targeted to S1PR1 (Ambion: Cat. no. s4447, s4449; Dharmacon: Cat. no. M-003655-02-0005), S1PR3 (Ambion: Cat. no. s4453, s4455; Dharmacon: Cat. no. M-005208-02-0005), SR-B1 (Ambion: Cat. no. s2648, s2649), p38 mitogen-activated protein kinases (p38 MAPK, Ambion: Cat. no. s3585), extracellular signal-regulated kinase kinase (MEK, Ambion: Cat. no. s11167), Akt1 (Ambion: Cat. no. s659, s660), Akt2 (Ambion: Cat. no. s1215, s1217), Akt3 (Ambion: Cat. no. s19427, s19429), non-silencing control siRNA (Ambion: Cat. no. 4390843; Dharmacon: Cat. no. D001810-10-50) at a final concentration of 10 or $20 \mathrm{nmol} / \mathrm{L}$ for $72 \mathrm{~h}$ using Lipofectamine ${ }^{\circledR}$ RNAiMAX reagent (Invitrogen, 13778-150) in an antibiotic-free EGM-2 medium (without GA-1000). The transfection procedure was performed according to the manufacturer's transfection protocol. Efficiency of transfection was confirmed by using qRT-PCR and western blot analyses.

\section{Western blot analyses}


Western blot analyses were performed as described previously (26). HAECs were seeded at a density of $0.4 \times 10^{6}$ cells/well in 6 -well plates. The cells were reverse transfected with siRNA targeted to SR-B1, S1PR1, S1PR3, p38 MAPK, MEK, Akt1, Akt2, or Akt3 for $72 \mathrm{~h}$, or treated with FTY720 phosphate (FTY720-P, Cayman: 10008639) or triciribine (Sigma, T3830) as indicated. To examine a putative liver X receptor (LXR), retinoid X receptor (RXR) and cyclic AMP (cAMP) dependency, the LXR agonist TO901317 $(10 \mu \mathrm{M})$, the RXR agonist bexarotene $(1 \mu \mathrm{M})$ and cAMP were used. The cells were lysed in ice-cold RIPA buffer with cOmplete ${ }^{\mathrm{TM}}$ protease inhibitor (Roche) and/or phosphatase inhibitors (Sigma, P0044) for $10 \mathrm{~min}$ before centrifugation (20 $817 \mathrm{~g}$ for $15 \mathrm{~min}$ ) to remove cellular debris. Concentration of total cellular protein was measured according to the $\mathrm{DC}^{\mathrm{TM}}$ protein assay according to the manufacturer's instruction (BIO-RAD).

Samples $(20 \mu \mathrm{g}$ total protein/sample) were loaded and separated via SDS-PAGE (10\%), and transferred to a polyvinylidene fluoride (PVDF, GE Healthcare) membrane. After blocking for $1 \mathrm{~h}$ with 5\% nonfat dry milk or BSA in PBS-Tween (PBST), membranes were incubated with the following primary antibodies at $4^{\circ} \mathrm{C}$ overnight: S1PR1 (Abcam: Cat. no. ab125074, 1:1000), S1PR2 (Abcam: Cat. no. ab125074, 1:500), S1PR3 (Abcam: Cat. no. ab108370, abcam, 1:1000), SR-B1 (Novus: Cat. no. NB400-131, 1:500), ABCG1 (Novus: Cat. no. NB400-132, 1:500), total Akt (Cell signalling: Cat. no. 9272s, 1:1000), phospho-Akt (Ser473) (Cell signalling: Cat. no. 9271, 1:1000), Akt1 (Cell signalling: Cat. no. 2938, 1:1000), Akt2 (Cell signalling: Cat. no. 3063, 1:1000), Akt3 (Cell signalling: Cat. no. 3788, 1:1000), MEK1/2 (Cell signalling: Cat. no. 8727, 1:2000), p38 MAPK (Cell signalling: Cat. no. 9212, 1:2000), or TATA-binding protein (TBP, Abcam: Cat. no. ab51841-100, 1:5000). After washing with PBST, membranes were incubated with polyclonal rabbit anti-goat immunoglobulins/HRP (Dako: Code no. P0449, 1:2000), polyclonal rabbit antimouse immunoglobulins/HRP (Dako: Code no. P0260, 1:1000), or polyclonal rabbit anti-rabbit immunoglobulins/HRP (Dako: Code no. P0448, 1:2000) at room temperature for $1 \mathrm{~h}$. Membranes were further incubated with chemiluminescence substrate (SuperSignal West Femto Maximum Sensitivity Substrate, or SuperSignal ${ }^{\mathrm{TM}}$ West Pico PLUS Chemiluminescent Substrate) for 1 minute (Thermo 
scientific). Protein bands were visualized with the Fusion FX UILBER LOURMAT (Vilber), and quantified with ImageJ software.

To measure SR-B1 protein stability, HAECs were seeded in 6-well plates as described above, and then cotreated with triciribine $(30 \mu \mathrm{M})$ and the protein synthesis inhibitor cycloheximide $(\mathrm{CHX}, 100 \mu \mathrm{M})$ for different time points $(0,1,2,3,4$, and $6 \mathrm{~h})$. The protein expression was detected by Western blot analyses. GraphPad Prism was applied to calculate the protein half-life $\left(\mathrm{t}_{1 / 2}\right)$.

\section{Quantitative reverse transcription-polymerase chain reaction (qRT-PCR)}

HAECs were seeded at a density of $0.4 \times 10^{6}$ cells/well in 6-well plates. Where indicated, cells were reverse transfected with siRNA targeted to SR-B1, S1PR1, S1PR3, p38 MAPK, MEK, Akt1, Akt2, or Akt3 for 72 h, or treated with FTY720-P or triciribine as indicated.

After transfection or drug treatment, total RNA was extracted from cells using TRI reagent (Sigma, T9424) according to the manufacturer's instruction. Concentration of total RNA was measured with NanoDrop 1000 (Witec AG). Genomic DNA was removed by digestion using DNase I Recombinant (Roche, 04716728001) and RiboLock RNase Inhibitor (Thermo Scientific, MAN0012010) according to the manufacturers' instructions. cDNA was synthesized from $1 \mu \mathrm{g}$ of total RNA by using the RevertAid Reverse Transcriptase kit. LightCycler ${ }^{\circledR} 480$ SYBR Green I Master kit was used for quantification of SRB1, S1PR1, S1PR2, and S1PR3 mRNA expression via the LightCycler ${ }^{\circledR} 480$ System (Roche). Relative mRNA levels were quantified with the $\Delta \mathrm{C}_{\mathrm{T}}$ method, using human GDPDH as an endogenous control. Gene specific primers were listed as followed: S1PR1 (Forward primer (For): GTC TGG AGT AGC GCC ACC; Reverse primer (Rev): GTA GTC AGA GAC CGA GCT GC), S1PR3 (For: TGA TCG GGA TGT GCT GGC; Rev: GAG TAG AGG GGC AGG ATG GTA), SCARB1 (For: CTG TGG GTG AGA TCA TGT GG; Rev: GCC AGA AGT CAA CCT TGC TC), GAPDH (For: CCC ATG TTC GTC ATG GGT GT; Rev: TGG TCA TGA GTC CTT CCA CGA TA).

\section{Cellular cAMP level assay}


HAECs were seeded at a density of $1 \times 10^{4}$ cells/well in 96 -well plates. The cells were reverse transfected with siRNA targeted to S1PR1, S1PR3 for $72 \mathrm{~h}$, and then treated with SEW2871 (Cayman Chemical, 50 nM), CYM5541 (Tocris Bioscience, $100 \mathrm{nM})$ or vehicle (0.1\% DMSO) for $1 \mathrm{~h}$ as indicated. The untreated cells were used as a control. cAMP-Glo ${ }^{\mathrm{TM}}$ Assay kit (Promega, Cat. no. V1501) was used to measure cellular cAMP levels via GloMax ${ }^{\circledR}$ Discover Microplate Reader (Promega, Cat. no. GM3000) according to the manufacturer's instruction. The luminescence output of the assay was calculated by the change in relative luminescence $(\triangle \mathrm{RLU}=\mathrm{RLU}$ (untreated sample) $-\mathrm{RLU}$ (treated sample)). Using these $\Delta \mathrm{RLU}$ values and the linear equation generated from the standard curve (cAMP), calculate the cellular cAMP concentrations.

\section{Cellular association of HDL}

The radiolabeled HDL cellular association assay was performed in line with previously published studies (27). HDL $(1.063<$ density $<1.210 \mathrm{~g} / \mathrm{ml})$ was isolated from human plasma of blood healthy donors by sequential ultracentrifugation $(28,29)$. HDL was labeled with $\mathrm{Na}^{125} \mathrm{I}$ by using the McFarlane monochloride methods modified for lipoproteins $(29,30)$. Specific activities of radiolabeled HDL were between 200-800 $\mathrm{cpm} / \mathrm{ng}$ of protein. HAECs were seeded at a density of $0.1 \times 10^{6}$ cells/well in 24 -well plates. Cells were reverse transfected with siRNA targeted to SR-B1, S1PR1 or S1PR3, or non-silencing control siRNA (NC siRNA) for $72 \mathrm{~h}$ as described above. After siRNA transfection, the cells were incubated with $10 \mu \mathrm{g} / \mathrm{mL}$ of ${ }^{125} \mathrm{I}-\mathrm{HDL}$ without (total) or with (unspecific) $400 \mu \mathrm{g} / \mathrm{mL}$ (40×) of non-labeled HDL in DMEM medium (25 $\mathrm{mmol} / \mathrm{L}$ HEPES, $100 \mathrm{U} / \mathrm{ml}$ benzylpenicillin, $100 \mu \mathrm{g} / \mathrm{ml}$ streptomycin, and $0.2 \% \mathrm{BSA}$ ) for $1 \mathrm{~h}$ at $37^{\circ} \mathrm{C}$ for HDL cellular association experiments. Specific HDL cellular association $=($ The total value $(\mathrm{cpm})$ unspecific value $(\mathrm{cpm})) /$ protein content

\section{Statistical analysis}

For determination of differences between two groups, a two-tailed unpaired Student's $t$-test was applied after data were tested for normality. For multiple comparisons, data were analyzed by one-way ANOVA 
bioRxiv preprint doi: https://doi.org/10.1101/2020.04.23.058263; this version posted April 24, 2020. The copyright holder for this preprint (which was not certified by peer review) is the author/funder. All rights reserved. No reuse allowed without permission.

followed by Bonferroni test to compare means between groups. $P<0.05$ was considered statistically significant. GraphPad Prism (Version 8.0.0, GraphPad Inc., La Jolla, CA) was used for statistical analysis and figure generation. 


\section{RESULTS}

\section{Down-regulation of S1PR1 or S1PR3 protein decreases SR-B1 expression in HAECs}

On both the mRNA and protein level, we found HAECs to express S1PR1 and S1PR3 at significant amounts, whereas S1PR2 was hardly detectable (Supplemental Figures S1). RNA interference decreased the expression of both S1PR1 and S1PR3 by $79 \%$ to $85 \%$ on the mRNA level and by $49 \%$ to $51 \%$ on the protein

level (Supplemental Figures S1). Knockdown of S1PR1 or S1PR3 decreased both SR-B1 protein and mRNA expression by $71 \%$ to $84 \%$ and $56 \%$ to $61 \%$, respectively, compared to non-coding siRNA (Figures $1 \mathrm{~A}$ and 1B). The respective percentages were higher than $90 \%$ for silencing of SCARB1. Furthermore, knockdown of S1PR1 or S1PR3 significantly decreased cellular association of ${ }^{125}$ I-HDL with HAECs by $18 \%$ to $19 \%$ compared to $28 \%$ upon knock-down of SCARB1 (Figure 1C).

To confirm the effects of loss-of-S1PR-function on SR-B1 expression, we applied FTY720-P, which induces degradation of S1PRs during long term treatment of cells (31). Incubation with 10 nM FTY720-P down-regulated protein levels of both SR-B1 and S1PR1 in a time dependent manner by up to $38 \%$ and $27 \%$, respectively (Figure 2A and 2B). During $24 \mathrm{~h}$ incubation, the suppression of SR-B1 mRNA by FTY720-P was dose dependent with a maximum of 56\% seen at $100 \mathrm{nM}$ (Figure 2C). The $43 \%$ suppression of SR-B1 protein however was already maximal at $10 \mathrm{nM}$ (Figure 2D).

Taken together the data indicate that both knockdown and pharmacological inhibition of S1PR1 or S1PR3 down-regulate both SR-B1 protein and mRNA levels. Of note, SR-B1 protein expression was suppressed more pronouncedly than SCARB1 mRNA.

\section{Decrease of S1PR1 or S1PR3 reduces SR-B1 protein expression on a post-transcriptional level via}

\section{Akt in HAECs}

S1PRs were shown to activate various signaling pathways, including Akt (protein kinase B), MEK, p38 MAPK and among others (25). We observed that the knockdown of either S1PR1 or S1PR3 slightly but significantly decreased p-Akt (Ser473) protein levels (Figure 3A). To unravel the signaling pathway by 
which S1PR1 and S1PR3 regulate SR-B1 expression in HAECs, we used triciribine to inhibit Akt activity and siRNAs against three Akt isoforms as well as siRNAs against MEK or p38 MAPK. Silencing of MEK or p38 MAPK did not influence SR-B1 protein level in HAECs (Supplemental Figure S2). Triciribine (10 and $30 \mu \mathrm{M}$ ) significantly decreased protein level of both phospho-Akt (p-Akt) and SR-B1 by around 65\% and $40-45 \%$ respectively already after $1 \mathrm{~h}$ of incubation (Figure 3B). The effect persisted for $8 \mathrm{~h}$ (Figure 3B). However, triciribine (10 and $30 \mu \mathrm{M}$ ) did not influence SCARB1 mRNA levels (Figure 3C). Knockdown of Akt1 but not Akt 2 or Akt3 significantly down-regulated SR-B1 protein expression by 44\% (20 nM siRNA) (Figure 3D-F). Since Akt is known to activate forkhead box class O family member protein 1 (FoxO1 transcription factors which in turn increases SCARB1 expression in liver (32), we also tested the effect of FoxO1 knockdown on the expression of SCARB1/SR-B1. Neither SCARB1 mRNA nor SR-B1 protein levels were changed (Supplemental Figure S2C-E). Taken together, the data suggest that Akt1 regulates SR-B1 protein levels post-translationally. We therefore investigated the impact of Akt inhibition by triciribine on SR-B1 protein stability by suppressing de novo protein synthesis with cycloheximide (100 $\mu \mathrm{M})$ and detecting SR-B1 protein levels at different time points $(0,1,2,3,4$, and $6 \mathrm{~h})$. The protein half-life $\left(\mathrm{t}_{1 / 2}\right)$ for SR-B1 in the absence and presence of triciribine were 3.8 and $2.1 \mathrm{~h}$, respectively (Figure $\left.3 \mathrm{G}\right)$. Thus, the decreased SR-B1 protein level induced by triciribine was due to enhanced degradation. Taken together, the data suggest that knockdown of S1PR1 or S1PR3 reduced SR-B1 protein partly by inducing SR-B1 protein degradation through deceasing Akt activity.

\section{Silencing of S1PR1 or S1PR3 reduces SR-B1 transcriptional expression via cAMP in HAECs}

We next started to unravel the mechanism by which knock-down of S1PR1 and S1PR3 suppresses SCARB1 mRNA expression in HAECs. The established inducers of SCARB1 gene expression are LXR and RXR and the second messenger cAMP (15). Both the LXR activator TO901017 and the RXR activator bexarotene increased the expression of the positive control gene ABCG1 in HAECs, no matter whether or not S1PR1 or S1PR3 were silenced. However, TO901017 and bexarotene neither altered SR-B1 expression under baseline condition nor rescued the loss of SR-B1 expression after S1PR knockdown (Supplemental Figure 
S3). However, the exogenous addition of cAMP rescued both SR-B1 protein and SCARB1 mRNA expression reduced by S1PR1 or S1PR3 knockdown (Figure 4A and 4B). S1PR1 or S1PR3 knockdown reduced cellular levels of cAMP dramatically both in the presence or absence of S1PR1 (SEW2871) or S1PR3 agonists (CYM5541) (Figure 4C). These data indicate that silencing of S1PR1 and S1PR3 regulate SCARB1 mRNA expression by decreasing cellular cAMP levels. 


\section{DISCUSSION}

HDL exerts many vasoprotective functions on the endothelium including stimulation of nitric oxide production and angiogenesis and the maintenance of barrier functions towards leukocytes and macromolecules (33). Several endothelial responses of endothelial cells to HDL have been shown to depend on the presence of S1PRs as well as SR-B1 $(18,20-24)$. As yet it is not clear whether these receptors act in parallel or in series. A transient triple interaction between HDL, SR-B1, and S1PRs was reported to elicit calcium flux and S1PR1 internalization (34). In this model, SR-B1 facilitates functions of S1P receptors. We here provide evidence for the additional converse relationship, namely that S1PR1 and S1PR3 regulate the abundance of SR-B1 in HAECs: Suppression or pharmacological inhibition of S1PR1 or S1PR3 downregulates SCARB1 mRNA expression as well as SR-B1 protein abundance. At least two pathways and mechanisms appear to be involved, one transcriptional involving cAMP and one post-translational involving Akt1 (Figure 5).

Endothelial cells express S1PR1, S1PR2, and S1PR3 (21), however to different extent in vessels of various tissues. S1PR2 was found to be the predominant S1P receptor expressed in human coronary artery endothelial cells (35). In our HAEC model, S1PR1 and S1PR3 were prominently expressed on the protein level whereas S1PR2 protein was hardly detectable. The data are in agreement with data of a previous study that found mRNAs of endothelial differentiation gene 1 (EDG1, S1PR1) and EDG2 (S1PR3) but not EDG5 (S1PR2) expressed in HAECs (36). We therefore focused our experiments on S1PR1 and S1PR3. Moreover, it is important to note that previous studies unraveled a specific role of S1PR1 for the endothelial effects of HDL-associated S1P, for example inhibition of VCAM and ICAM1 expression or decreasing permeability for macromolecules $(23,37-39)$.

In line with the findings of previous studies $(35,40,41)$, we observed that silencing of S1PR1 or S1PR3 decreases p-Akt (Ser473) protein expression in HAECs. Akt-phosphorylation is involved in several effects of both S1P and HDL on endothelial cells, namely the stimulation of NO production and angiogenesis as well as inhibition of adhesion molecule expression and apoptosis. All of these effects were also reported to involve SR-B1 $(20,21,23,24)$. We here show that Akt limits the degradation of SR-B1. In the presence of 
the Akt inhibitor triciribine, the half-life of SR-B1 in HAECs is shortened from about $4 \mathrm{~h}$ to about $2 \mathrm{~h}$. In this regard it is important to refer to another posttranslational effect of Akt on SR-B1: Previous cell surface biotinylation experiments of our lab showed that during 30 minutes of incubation VEGF-A promotes the translocation of SR-B1 from intracellular compartments to the cell surface by an Akt-dependent mechanism (12). Likewise, very short incubation of HAECs with agonists of S1PR1 or S1PR3 promote the translocation of intracellular SR-B1 to the cell surface (S. Velagapudi, et al., submitted for publication). Probably there are two post-translational pathways, by which Akt regulates the activity of SR-B1 in HAECs, namely the inhibition of degradation and the promotion of cell surface abundance. Akt also regulates the expression of SR-B1 in hepatocytes. In HepG2 cells, like in our HAECs, this happens on the posttranslational level (42). However, in mouse liver FoxOs transcription factors, which are activated by Akt, regulate the expression of SCARB1 (32). Of note, we did not find any involvement of FoxO1 transcription factors in the regulation of SCARB1 expression in HAECs, neither on the mRNA level nor on the protein level.

Independently of Akt, S1PR1 and S1PR3 also regulate SCARB1 expression on the transcriptional level. Transcription factors known to induce SCARB1 expression in different cell types include FoxOs (32) and cAMP response-element binding protein (CREB) (43). As mentioned before, we excluded any involvement of FoxO transcription factors in the regulation of SCARB1 in HAECs. Likewise and in contrast to previous findings in human umbilical vein endothelial cells (44), in our HAEC model, TO901317 and bexarotene did not increase the expression SCARB1 mRNA. Our data however suggest that the transcriptional regulation involves cAMP because RNA interference with S1PR1 or S1PR3 decreased cellular cAMP levels and because the suppression of SCARB1 by interference with S1PR1 or S1PR3 was prevented by the addition of exogenous cAMP. In agreement with our findings, cAMP was reported to increase SCARB1 mRNA expression in transfected $293 \mathrm{~T}$ cells (43), rat theca-interstitial cells (43) and adrenocortical cells (45). Moreover, in human coronary artery smooth muscle cells, S1P was shown to elicit cAMP accumulation, in a S1PR2 dependent manner (46). It remains to be unraveled how S1PR1/3 knockdown regulates cAMP level in HAECs, by stimulating an adenylate cyclase or inhibiting a phosphodiesterase. 
Both SR-B1 and S1PRs contribute to protective effects of HDL on the endothelium (47). However, SR-BI was also found to mediate transendothelial transport of both HDL and pro-atherogenic LDL (9-13). Also of note, the transendothelial transport of HDL and LDL is regulated by S1P3 into opposite directions: Activation and overexpression of S1PR3 in endothelial cells, promote the tranendothelial transport of HDL but inhibit the transendothelial transport of LDL in vitro and in vivo, respectively (Velagapudi, Wang, Poti et al. submitted for publication). Both endothelium-specific knock-out of Scarb1 and overexpression of SCARB1 was reported to reduce atherosclerosis in mice $(9,48)$. Likewise controversial data has been reported on the impact of modulated S1P metabolism or S1P receptor activity on atherosclerosis (49-54). The majority of data rather point to protective effects but none of them specifically investigated the endothelium-specific effects of S1P on atherosclerosis.

In conclusion, we here provide evidence for an as yet unappreciated interaction, namely the regulation of SR-B1 abundance by S1PRs on both transcriptional and post-translational levels. Together with previous observations indicating that SR-B1 facilitates S1PR activation, our findings help to solve the controversy on the role of S1P and its G-protein coupled receptors versus SR-B1 in mediating protective functions of HDL on the vasculature as well as transendothelial transport of HDL and LDL.

\section{Data availability statement}

All data are contained within the manuscript and supplemental data file.

\section{Acknowledgments/grant support}


This work was supported by grants from the Peter und Traudl Engelhorn Foundation for the promotion of Life Sciences to D.W. and the Swiss National Science Foundation(31003A-160216 and 310030_166391/1) to A.v.E.

\section{References}

1. Phillips, M. C. 2014. Molecular mechanisms of cellular cholesterol efflux. J Biol Chem 289: 2402024029.

2. Hoekstra, M., and M. Sorci-Thomas. 2017. Rediscovering scavenger receptor type BI: surprising new roles for the HDL receptor. Curr Opin Lipidol 28: 255-260.

3. Linton, M. F., H. Tao, E. F. Linton, and P. G. Yancey. 2017. SR-BI: A Multifunctional Receptor in Cholesterol Homeostasis and Atherosclerosis. Trends Endocrinol Metab 28: 461-472.

4. Valacchi, G., C. Sticozzi, Y. Lim, and A. Pecorelli. 2011. Scavenger receptor class B type I: a multifunctional receptor. Ann N Y Acad Sci 1229: E1-7.

5. Velagapudi, S., P. Schraml, M. Yalcinkaya, H. A. Bolck, L. Rohrer, H. Moch, and A. von Eckardstein. 2018. Scavenger receptor BI promotes cytoplasmic accumulation of lipoproteins in clear-cell renal cell carcinoma. J Lipid Res 59: 2188-2201.

6. Hu, J., Z. Zhang, W. J. Shen, and S. Azhar. 2010. Cellular cholesterol delivery, intracellular processing and utilization for biosynthesis of steroid hormones. Nutr Metab (Lond) 7: 47.

7. Wang, D., Y. Yang, Y. Lei, N. T. Tzvetkov, X. Liu, A. W. K. Yeung, S. Xu, and A. G. Atanasov. 2019. Targeting Foam Cell Formation in Atherosclerosis: Therapeutic Potential of Natural Products. Pharmacol Rev 71: 596-670.

8. Trigatti, B. L. 2017. SR-B1 and PDZK1: partners in HDL regulation. Curr Opin Lipidol 28: 201208. 
9. Huang, L., K. L. Chambliss, X. Gao, I. S. Yuhanna, E. Behling-Kelly, S. Bergaya, M. Ahmed, P. Michaely, K. Luby-Phelps, A. Darehshouri, L. Xu, E. A. Fisher, W. P. Ge, C. Mineo, and P. W. Shaul. 2019. SR-B1 drives endothelial cell LDL transcytosis via DOCK4 to promote atherosclerosis. Nature 569: $565-569$.

10. Mineo, C. 2019. Lipoprotein Receptor Signaling in Atherosclerosis. Cardiovasc Res.

11. Armstrong, S. M., M. G. Sugiyama, K. Y. Fung, Y. Gao, C. Wang, A. S. Levy, P. Azizi, M. Roufaiel, S. N. Zhu, D. Neculai, C. Yin, S. S. Bolz, N. G. Seidah, M. I. Cybulsky, B. Heit, and W. L. Lee. 2015. A novel assay uncovers an unexpected role for SR-BI in LDL transcytosis. Cardiovasc Res 108: 268277.

12. Velagapudi, S., M. Yalcinkaya, A. Piemontese, R. Meier, S. F. Norrelykke, D. Perisa, A. Rzepiela, M. Stebler, S. Stoma, P. Zanoni, L. Rohrer, and A. von Eckardstein. 2017. VEGF-A Regulates Cellular Localization of SR-BI as Well as Transendothelial Transport of HDL but Not LDL. Arteriosclerosis, thrombosis, and vascular biology 37: 794-803.

13. Rohrer, L., P. M. Ohnsorg, M. Lehner, F. Landolt, F. Rinninger, and A. von Eckardstein. 2009. High-density lipoprotein transport through aortic endothelial cells involves scavenger receptor BI and ATPbinding cassette transporter G1. Circulation research 104: 1142-1150.

14. Mineo, C., and P. W. Shaul. 2007. Role of high-density lipoprotein and scavenger receptor B type I in the promotion of endothelial repair. Trends Cardiovasc Med 17: 156-161.

15. Wang, D., J. Huang, T. Gui, Y. Yang, T. Feng, N. T. Tzvetkov, T. Xu, Z. Gai, Y. Zhou, J. Zhang, and A. G. Atanasov. 2020. SR-BI as a target of natural products and its significance in cancer. Semin Cancer Biol.

16. Tan, J. T., H. C. Prosser, L. L. Dunn, L. Z. Vanags, A. Ridiandries, T. Tsatralis, L. Lecce, Z. E. Clayton, S. C. Yuen, S. Robertson, Y. T. Lam, D. S. Celermajer, M. K. Ng, and C. A. Bursill. 2016. HighDensity Lipoproteins Rescue Diabetes-Impaired Angiogenesis via Scavenger Receptor Class B Type I. Diabetes 65: 3091-3103. 
17. Zhu, W., S. Saddar, D. Seetharam, K. L. Chambliss, C. Longoria, D. L. Silver, I. S. Yuhanna, P. W. Shaul, and C. Mineo. 2008. The scavenger receptor class B type I adaptor protein PDZK1 maintains endothelial monolayer integrity. Circulation research 102: 480-487.

18. Kimura, T., H. Tomura, C. Mogi, A. Kuwabara, A. Damirin, T. Ishizuka, A. Sekiguchi, M. Ishiwara, D. S. Im, K. Sato, M. Murakami, and F. Okajima. 2006. Role of scavenger receptor class B type I and sphingosine 1-phosphate receptors in high density lipoprotein-induced inhibition of adhesion molecule expression in endothelial cells. J Biol Chem 281: 37457-37467.

19. Yuhanna, I. S., Y. Zhu, B. E. Cox, L. D. Hahner, S. Osborne-Lawrence, P. Lu, Y. L. Marcel, R. G. Anderson, M. E. Mendelsohn, H. H. Hobbs, and P. W. Shaul. 2001. High-density lipoprotein binding to scavenger receptor-BI activates endothelial nitric oxide synthase. Nat Med 7: 853-857.

20. Proia, R. L., and T. Hla. 2015. Emerging biology of sphingosine-1-phosphate: its role in pathogenesis and therapy. J Clin Invest 125: 1379-1387.

21. Cartier, A., and T. Hla. 2019. Sphingosine 1-phosphate: Lipid signaling in pathology and therapy. Science 366.

22. Nofer, J. R., M. van der Giet, M. Tolle, I. Wolinska, K. von Wnuck Lipinski, H. A. Baba, U. J. Tietge, A. Godecke, I. Ishii, B. Kleuser, M. Schafers, M. Fobker, W. Zidek, G. Assmann, J. Chun, and B. Levkau. 2004. HDL induces NO-dependent vasorelaxation via the lysophospholipid receptor S1P3. J Clin Invest 113: 569-581.

23. Galvani, S., M. Sanson, V. A. Blaho, S. L. Swendeman, H. Obinata, H. Conger, B. Dahlback, M. Kono, R. L. Proia, J. D. Smith, and T. Hla. 2015. HDL-bound sphingosine 1-phosphate acts as a biased agonist for the endothelial cell receptor S1P1 to limit vascular inflammation. Science signaling 8: ra79.

24. Ruiz, M., H. Okada, and B. Dahlback. 2017. HDL-associated ApoM is anti-apoptotic by delivering sphingosine 1-phosphate to S1P1 \& S1P3 receptors on vascular endothelium. Lipids Health Dis 16: 36.

25. Nofer, J. R. 2015. Signal transduction by HDL: agonists, receptors, and signaling cascades. Handb Exp Pharmacol 224: 229-256. 
26. Wang, D., A. Tosevska, E. H. Heiss, A. Ladurner, C. Molzer, M. Wallner, A. Bulmer, K. H. Wagner, V. M. Dirsch, and A. G. Atanasov. 2017. Bilirubin Decreases Macrophage Cholesterol Efflux and ATPBinding Cassette Transporter A1 Protein Expression. J Am Heart Assoc 6.

27. Cavelier, C., P. M. Ohnsorg, L. Rohrer, and A. von Eckardstein. 2012. The beta-chain of cell surface $\mathrm{F}(0) \mathrm{F}(1)$ ATPase modulates apoA-I and HDL transcytosis through aortic endothelial cells. Arteriosclerosis, thrombosis, and vascular biology 32: 131-139.

28. Havel, R. J., H. A. Eder, and J. H. Bragdon. 1955. The distribution and chemical composition of ultracentrifugally separated lipoproteins in human serum. J Clin Invest 34: 1345-1353.

29. Rohrer, L., C. Cavelier, S. Fuchs, M. A. Schluter, W. Volker, and A. von Eckardstein. 2006. Binding, internalization and transport of apolipoprotein A-I by vascular endothelial cells. Biochim Biophys Acta 1761: 186-194.

30. Freeman, M., Y. Ekkel, L. Rohrer, M. Penman, N. J. Freedman, G. M. Chisolm, and M. Krieger. 1991. Expression of type I and type II bovine scavenger receptors in Chinese hamster ovary cells: lipid droplet accumulation and nonreciprocal cross competition by acetylated and oxidized low density lipoprotein. Proc Natl Acad Sci U S A 88: 4931-4935.

31. Oo, M. L., S. Thangada, M. T. Wu, C. H. Liu, T. L. Macdonald, K. R. Lynch, C. Y. Lin, and T. Hla. 2007. Immunosuppressive and anti-angiogenic sphingosine 1-phosphate receptor-1 agonists induce ubiquitinylation and proteasomal degradation of the receptor. J Biol Chem 282: 9082-9089.

32. Lee, S. X., M. Heine, C. Schlein, R. Ramakrishnan, J. Liu, G. Belnavis, I. Haimi, A. W. Fischer, H. N. Ginsberg, J. Heeren, F. Rinninger, and R. A. Haeusler. 2018. FoxO transcription factors are required for hepatic HDL cholesterol clearance. J Clin Invest 128: 1615-1626.

33. Luscher, T. F., U. Landmesser, A. von Eckardstein, and A. M. Fogelman. 2014. High-density lipoprotein: vascular protective effects, dysfunction, and potential as therapeutic target. Circulation research 114: 171-182.

34. Lee, M. H., K. M. Appleton, H. M. El-Shewy, M. G. Sorci-Thomas, M. J. Thomas, M. F. LopesVirella, L. M. Luttrell, S. M. Hammad, and R. L. Klein. 2017. S1P in HDL promotes interaction between 
SR-BI and S1PR1 and activates S1PR1-mediated biological functions: calcium flux and S1PR1 internalization. J Lipid Res 58: 325-338.

35. Liu, W., B. Liu, S. Liu, J. Zhang, and S. Lin. 2016. Sphingosine-1-phosphate receptor 2 mediates endothelial cells dysfunction by PI3K-Akt pathway under high glucose condition. Eur J Pharmacol 776: 19-25.

36. Kimura, T., T. Watanabe, K. Sato, J. Kon, H. Tomura, K. Tamama, A. Kuwabara, T. Kanda, I. Kobayashi, H. Ohta, M. Ui, and F. Okajima. 2000. Sphingosine 1-phosphate stimulates proliferation and migration of human endothelial cells possibly through the lipid receptors, Edg-1 and Edg-3. Biochem J 348 Pt 1: 71-76.

37. Ruiz, M., C. Frej, A. Holmer, L. J. Guo, S. Tran, and B. Dahlback. 2017. High-Density LipoproteinAssociated Apolipoprotein M Limits Endothelial Inflammation by Delivering Sphingosine-1-Phosphate to the Sphingosine-1-Phosphate Receptor 1. Arterioscler Thromb Vasc Biol 37: 118-129.

38. Nofer, J. R., M. Bot, M. Brodde, P. J. Taylor, P. Salm, V. Brinkmann, T. van Berkel, G. Assmann, and E. A. Biessen. 2007. FTY720, a synthetic sphingosine 1 phosphate analogue, inhibits development of atherosclerosis in low-density lipoprotein receptor-deficient mice. Circulation 115: 501-508.

39. Ruiz, M., C. Frej, A. Holmer, L. J. Guo, S. Tran, and B. Dahlback. 2017. High-Density LipoproteinAssociated Apolipoprotein M Limits Endothelial Inflammation by Delivering Sphingosine-1-Phosphate to the Sphingosine-1-Phosphate Receptor 1. Arteriosclerosis, thrombosis, and vascular biology 37: 118-129. 40. Safarian, F., B. Khallaghi, A. Ahmadiani, and L. Dargahi. 2015. Activation of S1P(1) receptor regulates PI3K/Akt/FoxO3a pathway in response to oxidative stress in PC12 cells. J Mol Neurosci 56: 177187.

41. Wang, H., H. Huang, and S. F. Ding. 2018. Sphingosine-1-phosphate promotes the proliferation and attenuates apoptosis of Endothelial progenitor cells via S1PR1/S1PR3/PI3K/Akt pathway. Cell Biol Int 42: $1492-1502$. 
42. Huang, C. X., Y. L. Zhang, J. F. Wang, J. Y. Jiang, and J. L. Bao. 2013. MCP-1 impacts RCT by repressing ABCA1, ABCG1, and SR-BI through PI3K/Akt posttranslational regulation in HepG2 cells. $J$ Lipid Res 54: 1231-1240.

43. Towns, R., and K. M. Menon. 2005. The role of cyclic AMP response element binding protein in transactivation of scavenger receptor class B type I promoter in transfected cells and in primary cultures of rat theca-interstitial cells. Mol Cell Endocrinol 245: 23-30.

44. Norata, G. D., M. Ongari, P. Uboldi, F. Pellegatta, and A. L. Catapano. 2005. Liver X receptor and retinoic $\mathrm{X}$ receptor agonists modulate the expression of genes involved in lipid metabolism in human endothelial cells. Int J Mol Med 16: 717-722.

45. Murao, K., H. Imachi, X. Yu, W. M. Cao, T. Muraoka, H. Dobashi, N. Hosomi, R. Haba, H. Iwama, and T. Ishida. 2008. The transcriptional factor prolactin regulatory element-binding protein mediates the gene transcription of adrenal scavenger receptor class B type I via 3',5'-cyclic adenosine 5'-monophosphate. Endocrinology 149: 6103-6112.

46. DAMIRIN, A., H. TOMURA, M. KOMACHI, M. TOBO, K. SATO, C. MOGI, H. NOCHI, K. TAMOTO, and F. OKAJIMA. 2004. Sphingosine-1-Phosphate Receptors Mediate the Lipid-Induced cAMP Accumulation Through Cyclooxygenase-2/Prostaglandin I2 Pathway in Human Coronary Artery Smooth Muscle Cells.

47. Pelletier, D., and D. A. Hafler. 2012. Fingolimod for multiple sclerosis. N Engl J Med 366: 339347.

48. Vaisman BL, Vishnyakova TG, Freeman LA, Amar MJ, Demosky SJ, Liu C, Stonik JA, Sampson ML, Pryor M, Bocharov AV, Eggerman TL, Patterson AP, Remaley AT. Endothelial Expression of Scavenger Receptor Class B, Type I Protects against Development of Atherosclerosis in Mice. Biomed Res Int. 2015;2015:607120. doi: 10.1155/2015/607120. Epub 2015 Oct 4. PubMed PMID: 26504816; PubMed Central PMCID: PMC4609362. 
49. Poti F, Ceglarek U, Burkhardt R, Simoni M, Nofer JR. Ski-ii--a sphingosine kinase 1 inhibitor-exacerbates atherosclerosis in low-density lipoprotein receptor-deficient (Idl-r-/-) mice on high cholesterol diet. Atherosclerosis. 2015;240:212-215

50. Bot M, Van Veldhoven PP, de Jager SC, Johnson J, Nijstad N, Van Santbrink PJ, Westra MM, Van Der Hoeven G, Gijbels MJ, Muller-Tidow C, Varga G, Tietge UJ, Kuiper J, Van Berkel TJ, Nofer JR, Bot I, Biessen EA. Hematopoietic sphingosine 1-phosphate lyase deficiency decreases atherosclerotic lesion development in Idl-receptor deficient mice. PLoS One. 2013;8:e63360

51. Christoffersen C, Jauhiainen M, Moser M, Porse B, Ehnholm C, Boesl M, Dahlback B, Nielsen LB. Effect of apolipoprotein $\mathrm{m}$ on high density lipoprotein metabolism and atherosclerosis in low density lipoprotein receptor knock-out mice. J Biol Chem. 2008;283:1839-1847

52. Poti F, Gualtieri F, Sacchi S, Weissen-Plenz G, Varga G, Brodde M, Weber C, Simoni M, Nofer JR. Krp-203, sphingosine 1-phosphate receptor type 1 agonist, ameliorates atherosclerosis in Idl-r-/- mice. Arterioscler Thromb Vasc Biol. 2013;33:1505-1512

53. Poti F, Costa S, Bergonzini V, Galletti M, Pignatti E, Weber C, Simoni M, Nofer JR. Effect of sphingosine 1-phosphate (s1p) receptor agonists fty 720 and cym5442 on atherosclerosis development in Idl receptor deficient (Idl-r(-)/(-)) mice. Vascul Pharmacol. 2012;57:56-64

54. Keul P, Tolle M, Lucke S, von Wnuck Lipinski K, Heusch G, Schuchardt M, van der Giet M, Levkau B. The sphingosine-1-phosphate analogue fty 720 reduces atherosclerosis in apolipoprotein e-deficient mice. Arteriosclerosis, thrombosis, and vascular biology. 2007;27:607-613 
Figures and figure legends
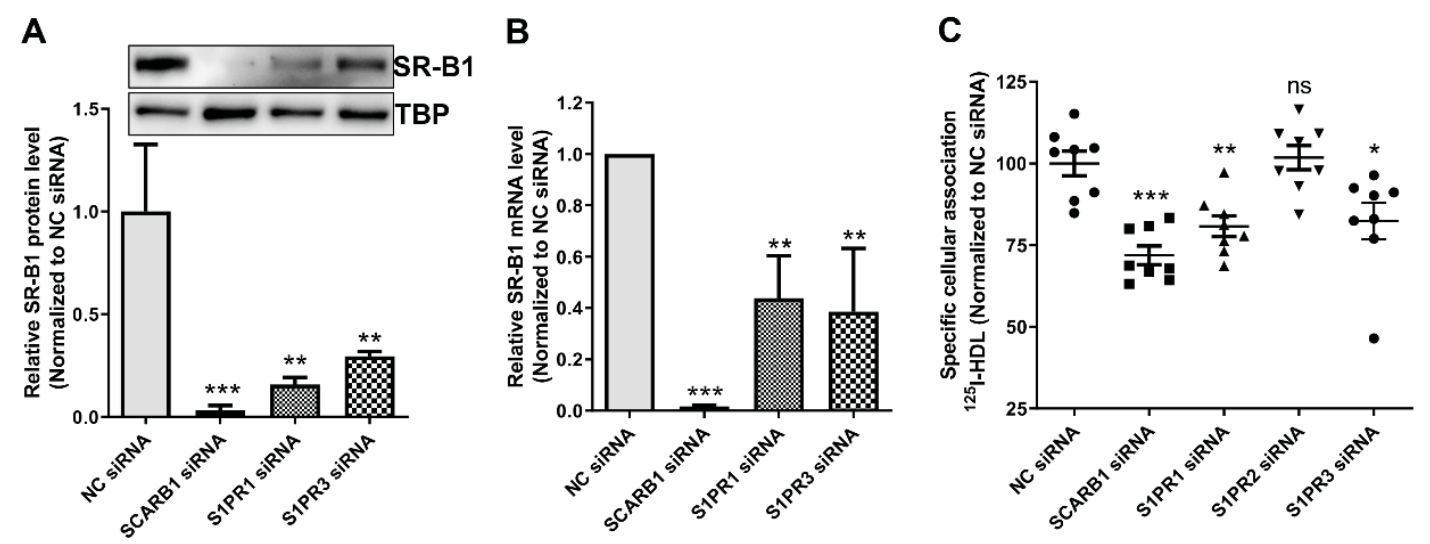

Figure 1. Knockdown of S1PR1 or S1PR3 protein decreases SR-B1 activity in HAECs. A and B.

Knockdown of S1PR1 or S1PR3 dramatically decreases both SR-B1 protein and mRNA expression. HAECs were seeded at a density of $0.4 \times 10^{6}$ cells/well in 6-well plates. The cells were reverse transfected with siRNA (10 nM) targeted to SR-B1, S1PR1 or S1PR3, or with non-silencing control siRNA (NC siRNA) for $72 \mathrm{~h}$. The expression of SR-B1 protein and mRNA was determined by western blot analyses and qRTPCR, respectively. TATA-binding protein (TBP) and GAPDH mRNA were used as the internal control for western blot analyses and RT-qPCR, respectively. C. Knockdown of S1PR1 or S1PR3 but not S1PR2 reduces endothelial HDL uptake. HAECs were seeded at a density of $0.1 \times 10^{6}$ cells/well in 24 -well plates. Cells were reverse transfected with siRNA $(10 \mathrm{nM})$ targeted to SR-B1, S1PR1 or S1PR3, or with NC siRNA for $72 \mathrm{~h}$. Cells were then incubated with $10 \mu \mathrm{g} / \mathrm{mL}$ of ${ }^{125} \mathrm{I}-\mathrm{HDL}$ for $1 \mathrm{~h}$ in the absence (total) or presence (unspecific) of 40-fold excess of unlabeled HDL. Specific HDL cellular association was calculated by subtracting unspecific values from total values. Data are shown as mean \pm SD from three independent experiments, each performed in triplicate in case of the HDL cellular association assay $(\mathbf{C}) . * \mathrm{P}<0.05$, **P $<0.01, * * \mathrm{P}<0.001$, and ns not significant (Student's $t$-test or ANOVA with Bonferroni test). 

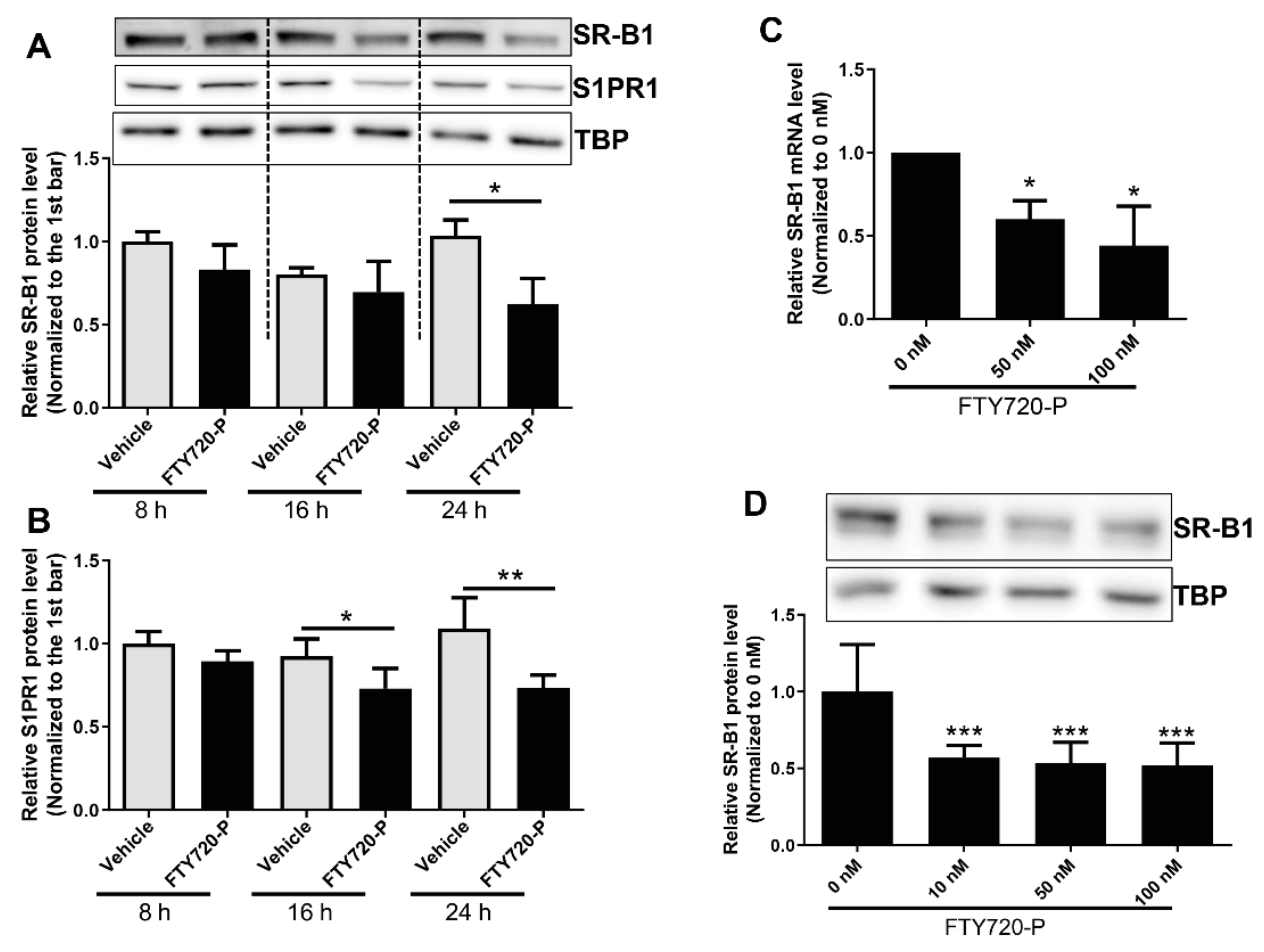

Figure 2. FTY720 phosphate (FTY720-P) decreases both SR-B1 protein and mRNA expression.

HAECs were seeded at a density of $0.4 \times 10^{6}$ cells/well in 6-well plates and treated with FTY720-P (A and B: $10 \mathrm{nM}$ for 8,16 or $24 \mathrm{~h}$; C and D: $0-100 \mathrm{nM}$ for $24 \mathrm{~h}$ ) or solvent vehicle (0.1\% DMSO). The expression of SR-B1 protein and mRNA was determined by western blot analyses and qRT-PCR, respectively. Data are shown as mean $\pm \mathrm{SD}$ from three independent experiments. ${ }^{\mathrm{P}}<0.05,{ }^{*} \mathrm{P}<0.01,{ }^{* *} \mathrm{P}<0.001$ (Student's t-test or ANOVA with Bonferroni test). 

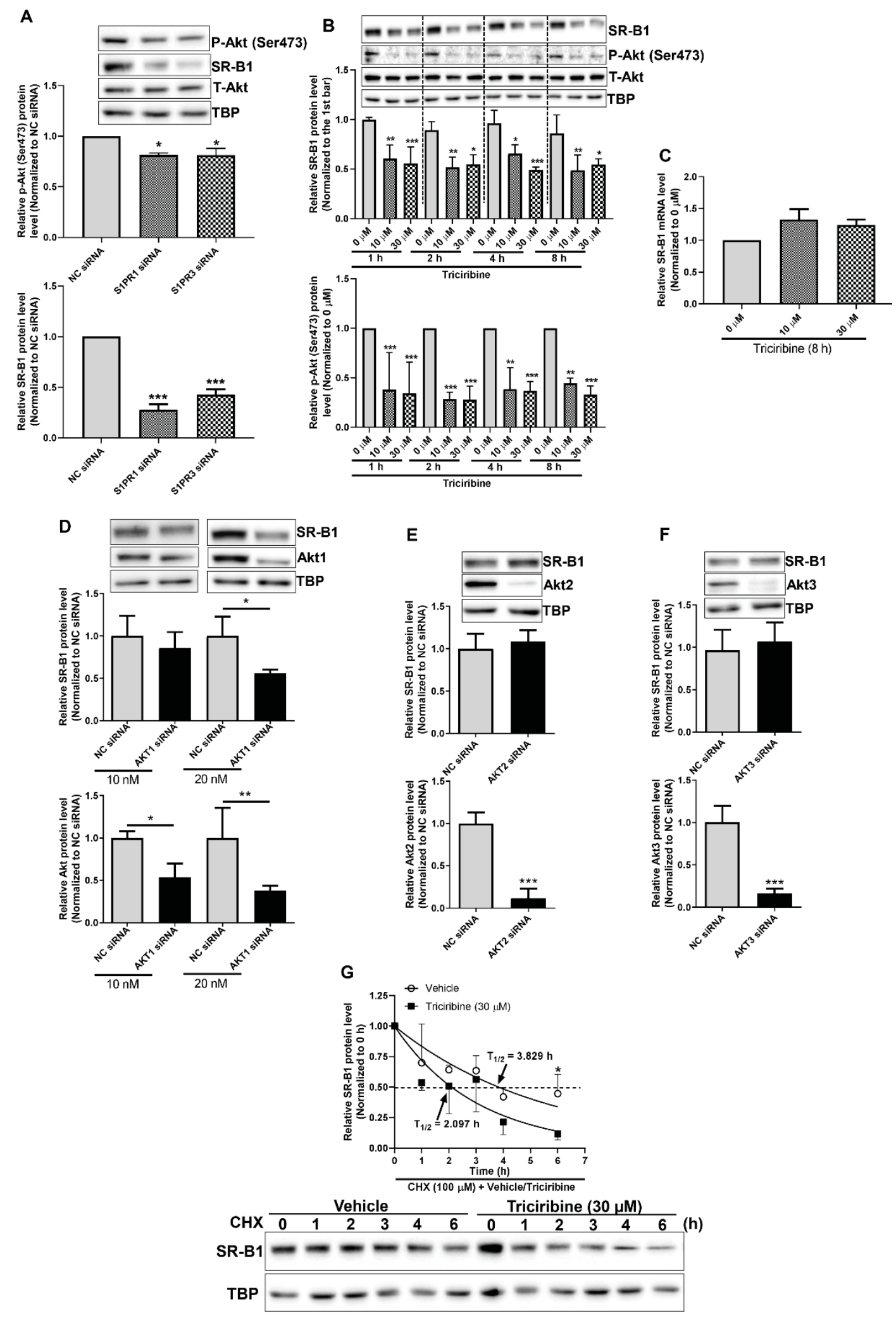
Figure 3. Decrease of S1PR1 or S1PR3 protein expression enhances SR-B1 protein degradation via inhibiting Akt activity in HAECs. A. S1PR1 or S1PR3 knockdown decreases phospho-Akt (p-Akt (Ser473)) protein level. HAECs were seeded and transfected with siRNA (10 nM) targeted to S1PR1 or S1PR3 as described in Figure 1A. The protein expression of SR-B1, p-Akt (Ser473), and total (T-Akt) was determined by western blot analyses. TBP was used as the internal control. B. The Akt inhibitor triciribine decreases SR-B1 protein expression along with down-regulation of p-Akt (Ser473) expression. HAECs were seeded at a density of $0.4 \times 10^{6}$ cells/well in 6-well plates for $72 \mathrm{~h}$. The cells were treated with triciribine $(0-30 \mu \mathrm{M})$ for 1, 2, 4 or $8 \mathrm{~h}$. The expression of SR-B1, p-Akt (Ser473), and T-Akt protein was determined by western blot analyses. TBP was used as the internal control. C. Triciribine does not influence SR-B1 mRNA level. HAECs were seeded at a density of $0.4 \times 10^{6}$ cells/well in 6-well plates for $72 \mathrm{~h}$. The cells were treated with triciribine $(0-30 \mu \mathrm{M})$ for $8 \mathrm{~h}$. The expression of SR-B1 mRNA was determined by qRT-PCR. GAPDH mRNA was used as the internal control. D, E and F. Knockdown of Akt1, but not Akt2 or 3, decreases SR-B1 protein expression. HAECs were seeded and transfected with siRNA targeted to Akt1 (10 and $20 \mathrm{nM})$, Akt2 (10 nM) or Akt3 $(10 \mathrm{nM})$ as described in Figure 1A. The protein expression of SR-B1, Akt1, 2 and 3 was determined by western blot analyses. G. Triciribine enhances SR-B1 protein degradation rate. HAECs were seeded as described in Figure 3A. Cells were lysed at different time points $(0,1,2,3,4$, and $6 \mathrm{~h})$ after incubation with the de novo protein synthesis inhibitor cycloheximide (CHX, $100 \mu \mathrm{M})$ and triciribine $(30 \mu \mathrm{M})$ or vehicle $(0.1 \% \mathrm{DMSO})$. The SR-B1 protein expression was determined by western blot analyses. Data are shown as mean $\pm \mathrm{SD}$ from three independent experiments. $* \mathrm{P}<0.05$, $* * \mathrm{P}<0.01$ and $* * \mathrm{P}<0.001$ (Student's $t$-test or ANOVA with Bonferroni test). 

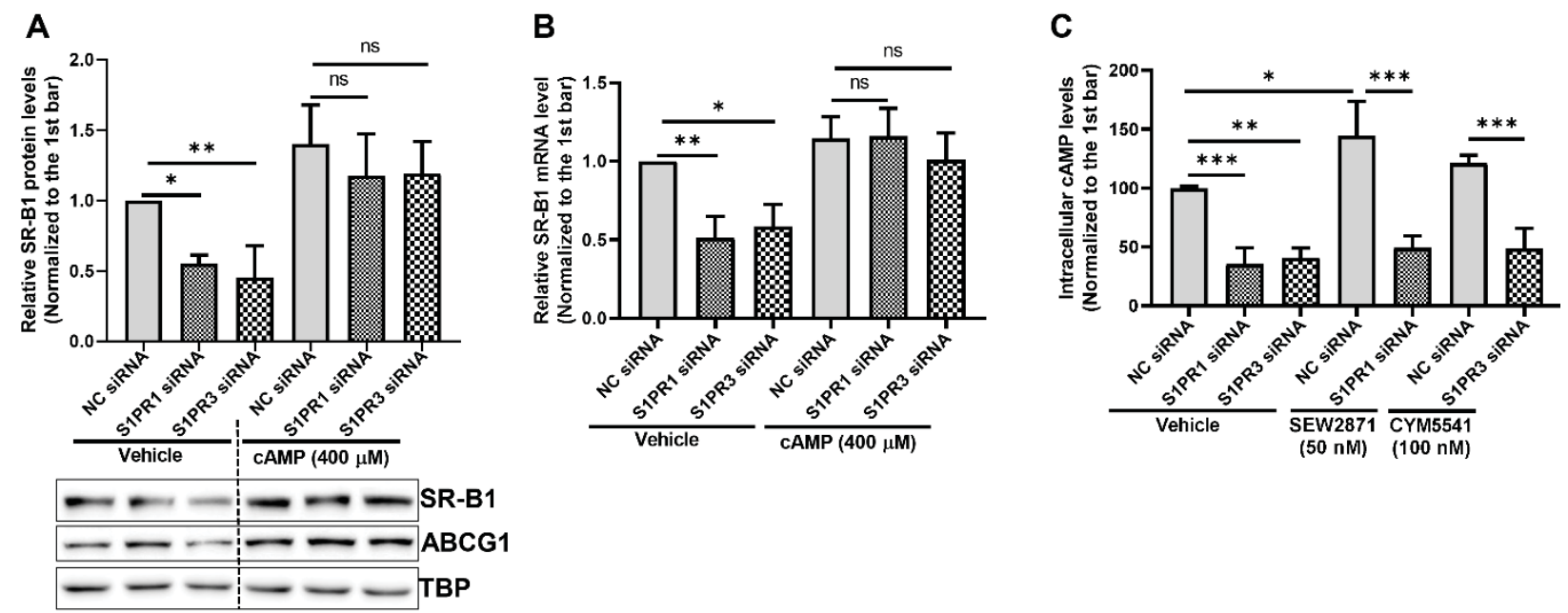

Figure 4. Knockdown of S1 PR1 or S1PR3 reduces mRNA expression of SCARB1 via cAMP in HAECs.

A and B. Exogenous addition of cAMP rescues the protein and mRNA levels of SR-B1 reduced by S1PR1 or S1PR3 knockdown. HAECs were seeded and transfected with siRNA (10 nM) targeted to S1PR1 or S1PR3, or with NC siRNA as for $48 \mathrm{~h}$ described in Figure 1A. The cells were then treated with cAMP (400 $\mu \mathrm{M})$ or vehicle $(0.1 \% \mathrm{DMSO})$ for $16 \mathrm{~h}$. The protein and mRNA levels of SR-B1 were determined by western blot analyses and qRT-PCR, respectively. ABCG1 protein expression was used to confirm the positive effect of cAMP. C. S1PR1 or S1PR3 knockdown reduces cellular cAMP level in the presence or absence of the S1PR1 (SEW2871) or S1PR3 agonists (CYM5541). HAECs were seeded and transfected with siRNA (10 nM) targeted to S1PR1 or S1PR3, or with NC siRNA as for $72 \mathrm{~h}$ described in Figure 1A. The cells were then treated with SEW2871 (50 nM), CYM5541 (100 nM) or vehicle (0.1\% DMSO) for $1 \mathrm{~h}$. The cellular cAMP level was measured by using cAMP-Glo ${ }^{\text {TM }}$ Assay kit. Data are shown as mean \pm SD from three independent experiments. $* \mathrm{P}<0.05,{ }^{*} \mathrm{P}<0.01,{ }^{*} * \mathrm{P}<0.001$, and ns not significant (Student's t-test or ANOVA with Bonferroni test). 


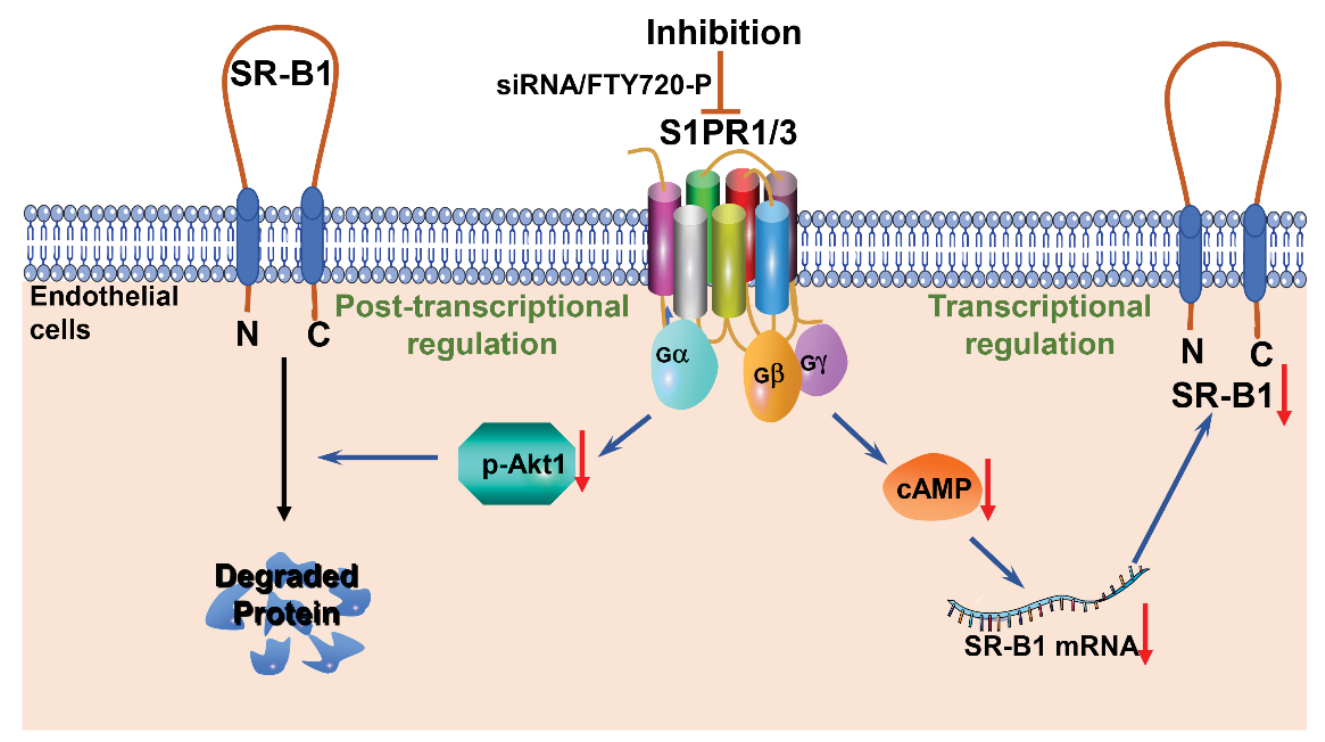

Figure 5. Loss of function of S1PR1 or S1PR3 limits SR-B1 expression in HAECs on the transcriptional and posttranslational levels. First, loss of S1PR1 or S1PR3 activity enhances SR-B1 protein degradation via decreased phosphorylation of Akt1. Second, silencing of S1PR1 or S1PR3 suppresses SCARB1 mRNA and, as the consequence, SR-B1 protein levels, by a decrease in cAMP. 

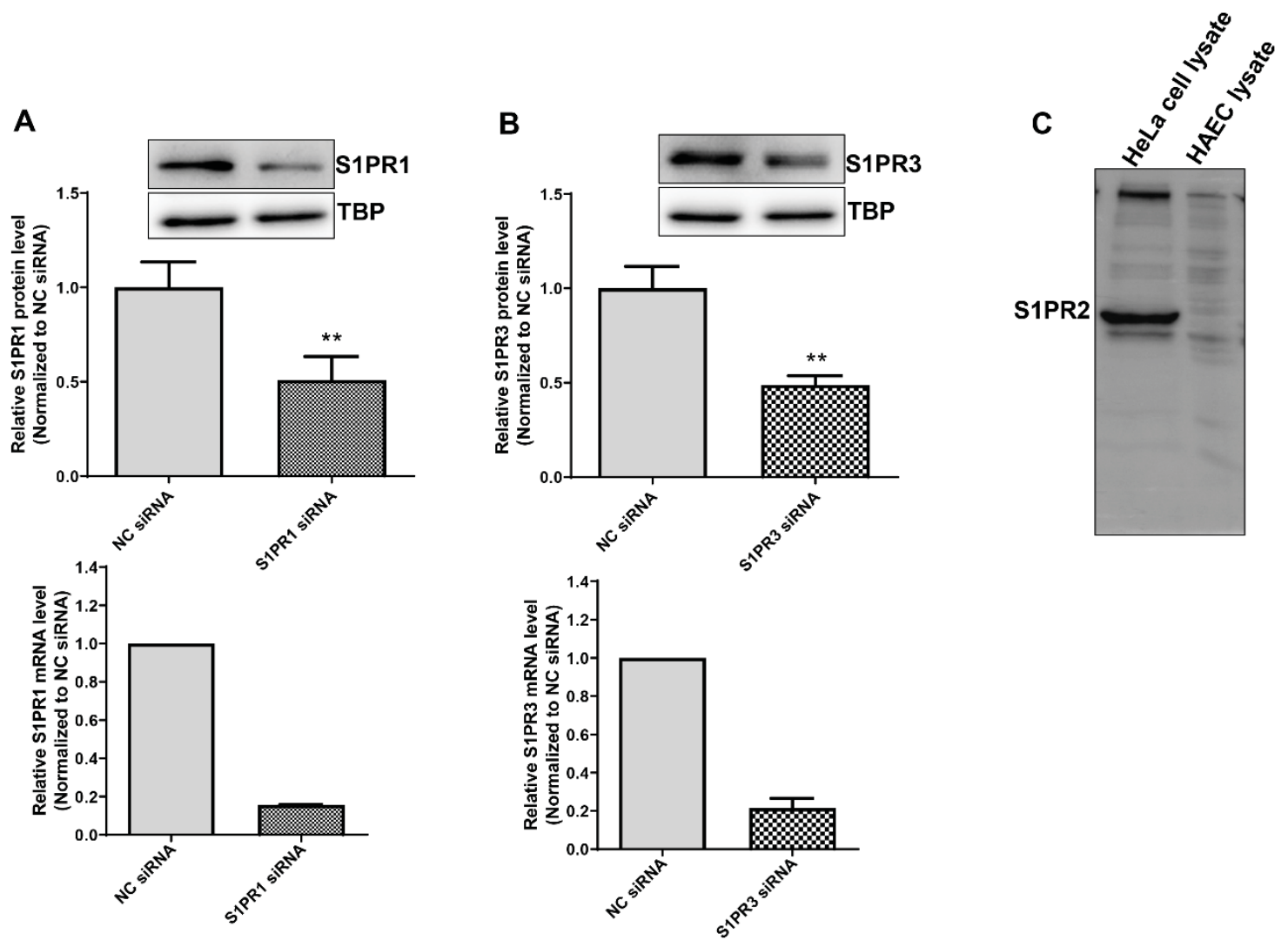

\section{Supplemental Figure S1. A and B. Knockdown efficiency of S1PR1 and S1PR3 in HAECs. HAECs}

were seeded at a density of $0.4 \times 10^{6}$ cells/well in 6 -well plates. The cells were reverse transfected with siRNA (10 nM) targeted to SR-B1, S1PR1 or S1PR3, or with non-silencing control siRNA (NC siRNA) for $72 \mathrm{~h}$. The expression of SR-B1 protein and mRNA was determined by western blot analyses and RTqPCR, respectively. TATA-binding protein (TBP) and GAPDH mRNA were used as the internal control for western blot analyses and RT-qPCR, respectively. Data are shown as mean $\pm \mathrm{SD}$ from three independent experiments. $* * \mathrm{P}<0.01$ (Student's $t$-test). C. Low expression of S1PR2 protein in HAECs. Hela cell lysate is as a positive control, which over-expressed S1PR2 protein. 
A

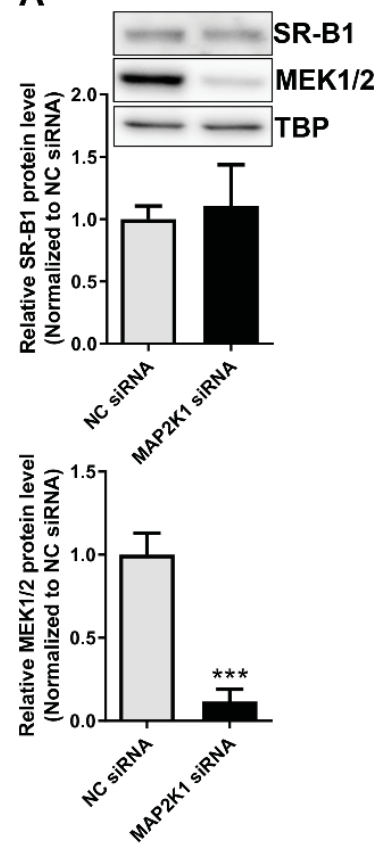

B

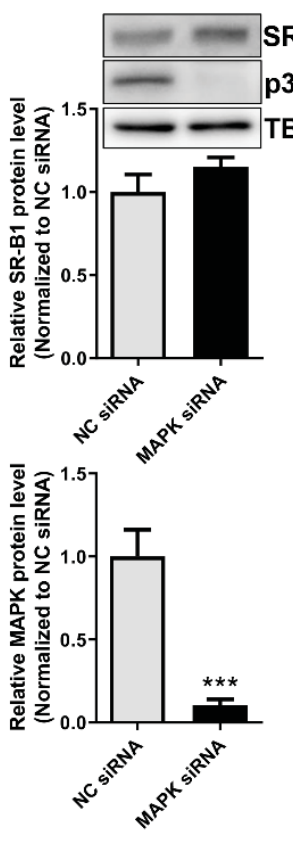

C
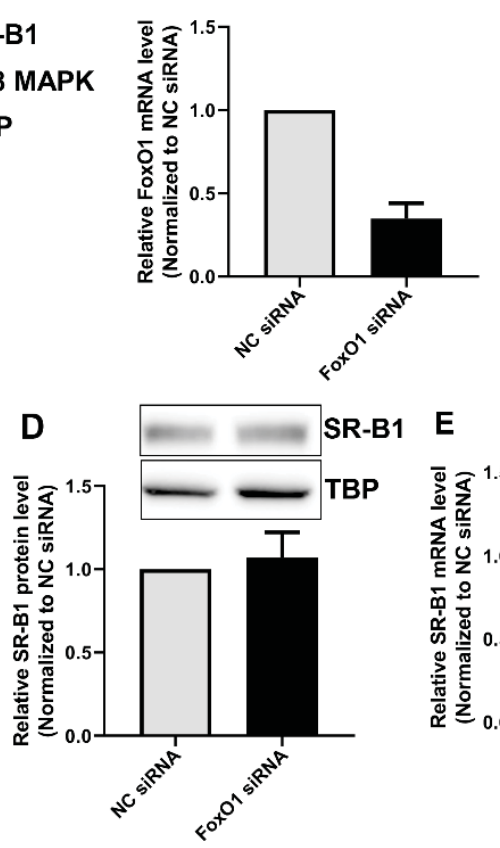

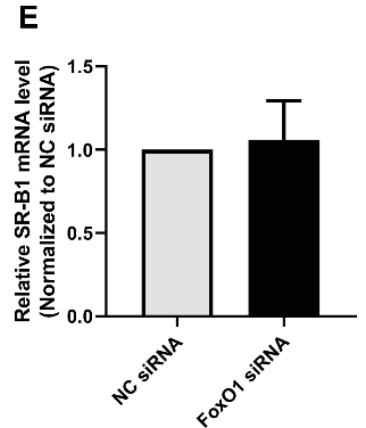

Supplemental Figure 2S. A and B. Knockdown of MEK1/2 (A) or p38 MAPK (B) does not influence

SR-B1 protein expression in HAECs. HAECs were seeded and transfected with siRNA $(10 \mathrm{nM})$ targeted to MEK1/2, or p38 MAPK as described in Figure 1S. The protein expression of SR-B1, MEK1/2 and p38 MAPK was determined by western blot analyses. TBP was used as the internal control. The data of samples were normalized to NC siRNA. C-E. Knockdown of FoxO1 does not influence SR-B1 mRNA and protein expression in HAECs. HAECs were seeded and transfected with siRNA $(10 \mathrm{nM})$ targeted to FoxO1 as described in Figure 1S. The protein expression of FoxO1 was determined by western blot analyses. TBP was used as the internal control. The data of samples were normalized to NC siRNA. Data are shown as mean $\pm \mathrm{SD}$ from three independent experiments. $* * * \mathrm{P}<0.001$ (Student's $t$-test). 

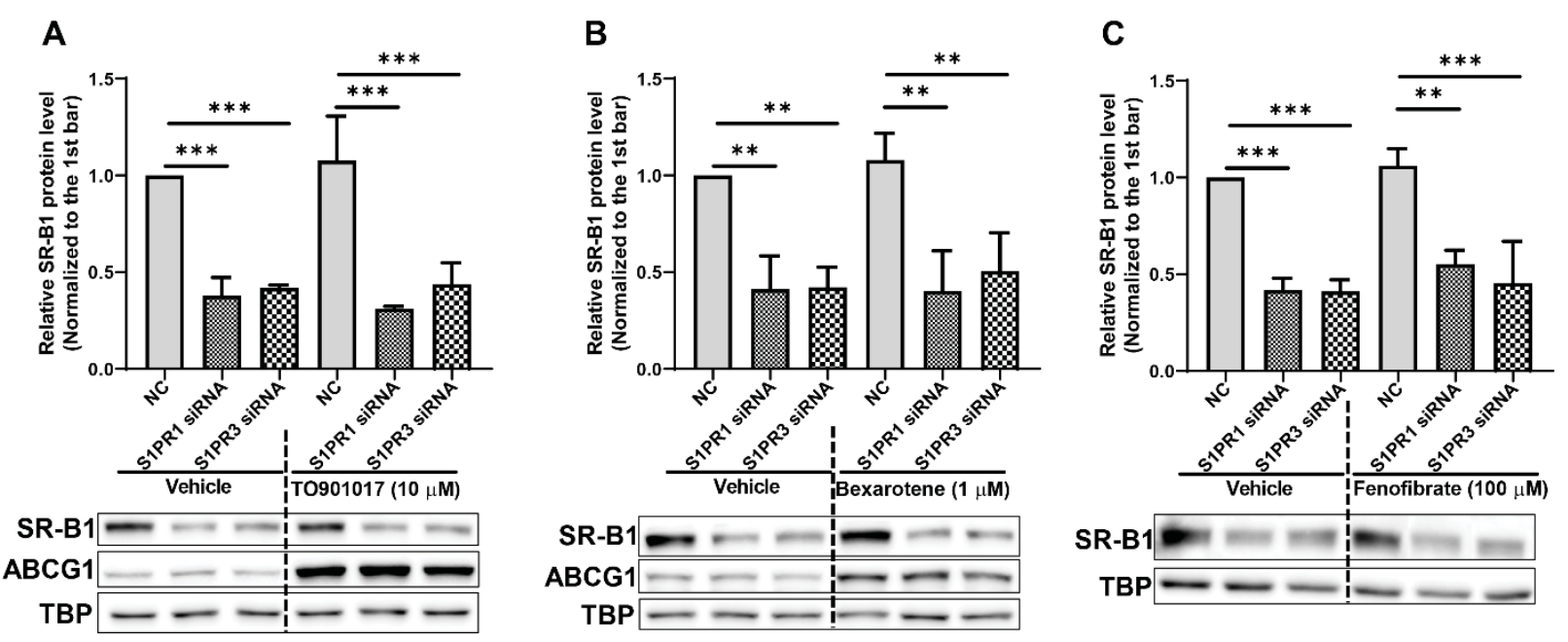

Supplemental Figure S3. Activation of LXR or RXR does not restore SR-B1 protein level reduced by

S1PR1 or S1PR3 knockdown. HAECs were seeded and transfected with siRNA (10 nM) targeted to S1PR1 or S1PR3, or with NC siRNA as for $48 \mathrm{~h}$ described in Figure S1. The cells were then treated with the LXR agonist TO901017, RXR agonist bexarotene, or vehicle (0.1\% DMSO) for $16 \mathrm{~h}$. The SR-B1 and ABCG1 protein expression were determined by western blot analyses. ABCG1 protein expression was used to confirm the positive effect of T0901017 and bexarotene. Data are shown as mean \pm SD from three independent experiments. ${ }^{*} \mathrm{P}<0.01$, and $* * * \mathrm{P}<0.001$ (Student's $t$-test or ANOVA with Bonferroni test). 